\title{
Application of Different Analytical Techniques and Microbiological Assays for the Analysis of Macrolide Antibiotics from Pharmaceutical Dosage Forms and Biological Matrices
}

\author{
Lantider Kassaye Bekele and Getachew Genete Gebeyehu \\ Food and Drug quality Control Laboratory, Food, Medicine and Health Care Administration and Control Authority of Ethiopia,
} Addis Ababa 5681, Ethiopia

Correspondence should be addressed to Lantider Kassaye Bekele, ethiolk@yahoo.com

Received 7 March 2012; Accepted 2 May 2012

Academic Editors: I. Lavilla and I. Zhukov

Copyright ( 2012 L. K. Bekele and G. G. Gebeyehu. This is an open access article distributed under the Creative Commons Attribution License, which permits unrestricted use, distribution, and reproduction in any medium, provided the original work is properly cited.

Macrolides are a group of drugs whose activity stems from the presence of a macrolide ring, a large macrocyclic lactone ring to which one or more deoxy sugars may be attached. They are produced by Streptomyces species and used primarily against gram-positive bacteria. The determination of antibiotics, including macrolides, is mainly carried out by microbiological assays. However, microbiological assays tended to lack specificity. And hence to overcome this problem, lots of chemical and instrumental methods have been developed to determine macrolides separately as well as simultaneously. Different chromatographic, spectrophotometric, and electrochemical methods used for the determination of macrolides have been reviewed in this paper.

\section{Introduction}

Antibiotics are substances produced by microorganisms, which suppress the growth of or kill other microorganisms at very low concentrations [1]. Antibiotics can be classified as $\beta$-lactam antibiotics, amino glycosides, macrolide antibiotics, tetracyclines, polyene antibiotics, nitro furan derivatives, and so on based on their chemical structure.

Macrolides are a group of drugs that belong to the polyketide class of natural products and whose activity stems from the presence of a macrolide ring, a large macrocyclic lactone ring to which one or more deoxy sugars, usually cladinose or desosamine, may be attached. The lactone rings are usually 14,15 , or 16 -membered.

Macrolide antibiotics, produced by Streptomyces species, are used primarily against gram-positive bacteria. The use of macrolide antibiotics involves a range of problems such as the increase in the resistance of gram-positive and gram negative strains, slow bactericidal action, associated gastrointestinal disturbance, allergic reactions, and hepatotoxic effects [2, 3]. Therefore, the number of novel 14-, 15-, and 16-membered macrolides has been increasing over the past few years [4]. The most commonly used macrolide antibiotics consist of a macrocyclic lactone ring containing 14,15 , or 16 atoms with sugars linked via glycosidic bonds [5].

All macrolides contain macrocyclic lactone ring to which one or more sugar is attached. Their pharmacodynamic properties are very similar and in general they have low toxicity and the same spectrum of antimicrobial activity with cross-resistance between individual members of the group. They are either bacteriostatic or bactericidal, depending on the concentration and type of microorganism, and interfere with the bacterial protein synthesis. Their antimicrobial 
spectrum is similar with that of penicillins, but they are also active against Legionella pneumophila, Mycoplasma pneumonia, and some Rickettisias and Chlamydias [6].

1.1. Members of Macrolide Antibiotics. The clinically useful macrolide antibiotics can be conveniently classified into three groups based on the number of atoms in the lactone nucleus.

\subsubsection{The 14-Membered Macrolide Antibiotics}

Erythromycin. Erythromycin (Figure 1(I)) was isolated from the metabolic products of a strain of Streptomyces erythreus by a group of Filipino scientist in 1949, which was found in soil sample. The product was launched commercially in 1952 under the brand name of ilosone. Erythromycin was formerly also called ilotycin.

Erythromycin is available in enteric-coated tablets, slowrelease capsules, oral suspensions, ophthalmic solutions, ointments, gels, and injections.

Clarithromycin. Clarithromycin (Figure 1(II)) was invented by scientists of the Japan Taisho Pharmaceutical company in the 1970s. The product emerged through efforts to develop a version of the antibiotic erythromycin that did not experience acid instability in the digestive tract and thereby cause side effects, such as nausea and stomach ache. Taisho filed for patent protection over its new drug around 1980 and subsequently introduced a branded version of its drug, called clarith, to the Japanese market in 1991. Clarithromycin is commonly administered in tablets and, extended-release tablets, oral suspension, or in a gel/lotion-based form for topical use.

Roxithromycin. Roxithromycin (Figure 1(III)) is a semisynthetic macrolide antibiotic, and it was brought out by German pharmaceutical company Hoechst Uclaf in 1987. It is used to treat respiratory tract, urinary, and soft tissue infections. Roxithromycin is derived from erythromycin, containing the same 14-membered lactone ring. However, an N-oxime side chain is attached to the lactone ring. It is also currently undergoing clinical trials for the treatment of male-pattern hair loss. Roxithromycin is commonly available as tablets or oral suspension.

Dirithromycin. Dirithromycin (Figure 1(IV)) is a more lipid-soluble prodrug derivative of 9S-erythromycyclamine, semisynthetic derivative of erythromycin, prepared by condensation of the latter with 2-(2-methoxyethoxy) acetaldehyde. The $9 \mathrm{~N}, 11 \mathrm{O}$-oxazine ring thus formed is unstable under both acidic and alkaline aqueous conditions and undergoes spontaneous hydrolysis to form erythromycyclamine. Erythromycyclamine retains the antibacterial properties of erythromycin oral administration. The prodrug, dirithromycin, is provided as enteric-coated tablets to protect it from acid catalyzed hydrolysis in the stomach. Orally administered dirithromycin is absorbed rapidly into the plasma, largely from the small intestine. Spontaneous hydrolysis to erythromycyclamine occurs in the plasma.

\subsubsection{The 15-Membered Macrolide Antibiotics}

Azithromycin. Azithromycin (Figure 2) is a subclass of macrolide antibiotics, which had been discovered by a team of Croatian pharmaceutical company, Pliva researchers in 1980. Azithromycin is one of the world's best-selling antibiotics and is derived from erythromycin; however, it differs chemically from erythromycin in that a methyl-substituted nitrogen atom is incorporated into the lactone ring, thus making lactone ring 15-membered.

Azithromycin is commonly administered in tablets or oral suspension forms. It is also available for intravenous injection.

1.1.3. The 16-Membered Macrolide Antibiotics. These are types of macrolides antibiotics, which contain 16 atoms in the lactone nucleus (Figure 3). These are Carbomycin A, Josamycin, Kitasamycin, Midecamycine acetate, Spiramycin, Troleandomycin, and Tylosin. However, these antibiotics are not commonly used like that of 14 and 15-membered groups. Most of them have also veterinary uses.

\subsection{Pharmacology of Macrolide Antibiotics}

Mechanism of Action. All macrolides have similar mechanism of action, which is inhibition of bacterial protein biosynthesis by binding irreversibly to the subunit 50-S of the bacterial ribosome, thereby inhibiting translocation of peptidyl t-RNA. This action is mainly bacteriostatic but can also be bactericidal in high concentrations. Macrolides tend to accumulate within leukocytes and are therefore actually transported into the site of infection [7].

Therapeutic Applications. Macrolides are used to treat infections such as respiratory tract and soft tissue infections. The antimicrobial spectrum of macrolides is slightly wider than that of penicillins, and therefore macrolides are a common substitute for patients with a penicillin allergy. Unlike penicillin, macrolides have been shown to be effective against mycoplasma, mycobacteria, some rickettsia, and chlamydia [8]. Clarithromycin is also used to treat gastric ulcers due to H. pylori as a component of multidrug combination [9].

Adverse Effects. Anorexia, nausea, vomiting, and diarrhea occasionally accompany oral administration. Gastrointestinal intolerance, which is direct stimulation of gut motility, is the most frequent reason for discontinuing these antibiotics.

Erythromycin, particularly the estolate, can produce acute cholestatic hepatitis (fever, jaundice, impaired liver function), probably as a hypertensive reaction [10]. Intravenous administration often results in thrombophlebitis, particularly if high dose is used. Allergic reactions, particularly skin rashes, rarely occur [11].

Other Activities of Macrolide Antibiotics. Macrolide antibiotics have a variety of actions other than antimicrobial activities. Recently, it has been suggested that macrolide antibiotics act as immunomodulators. Effects of macrolide antibiotics 


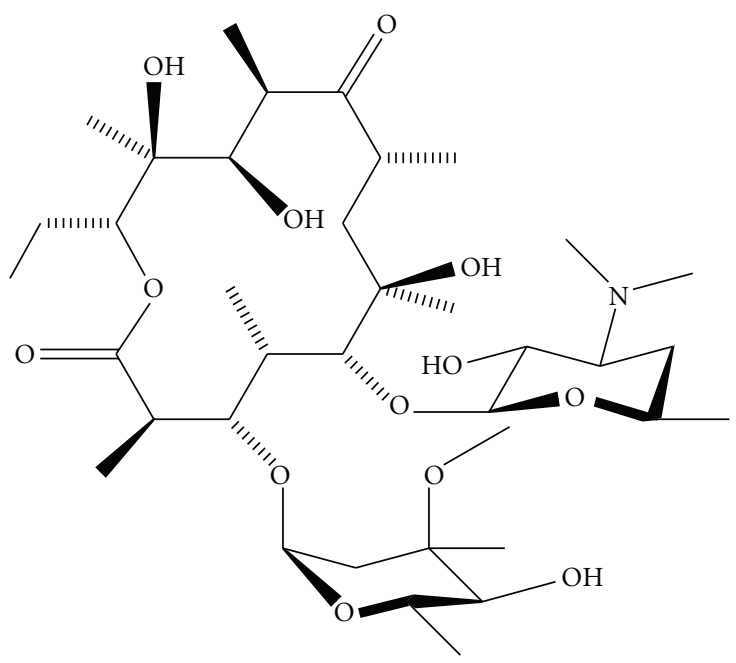

(I)

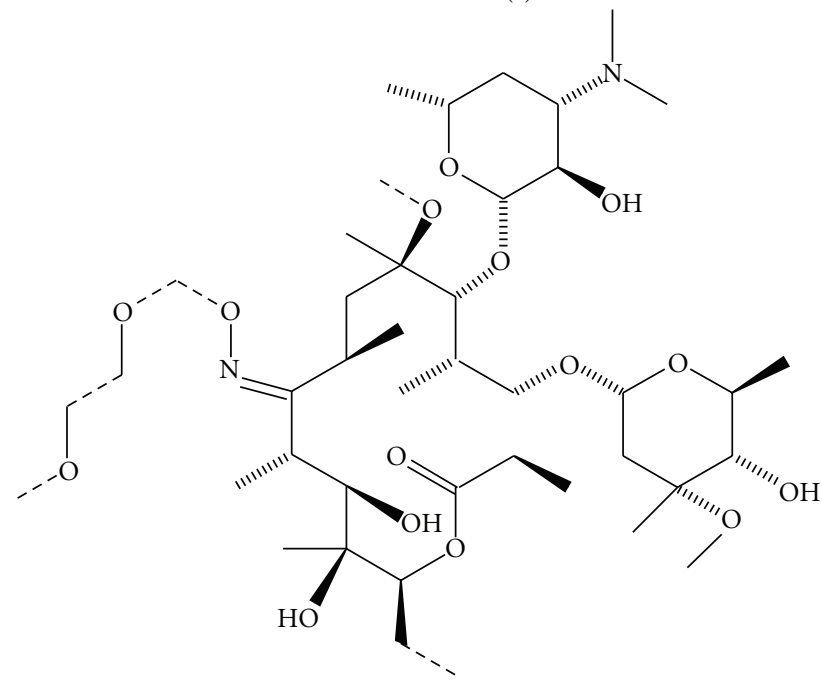

(III)

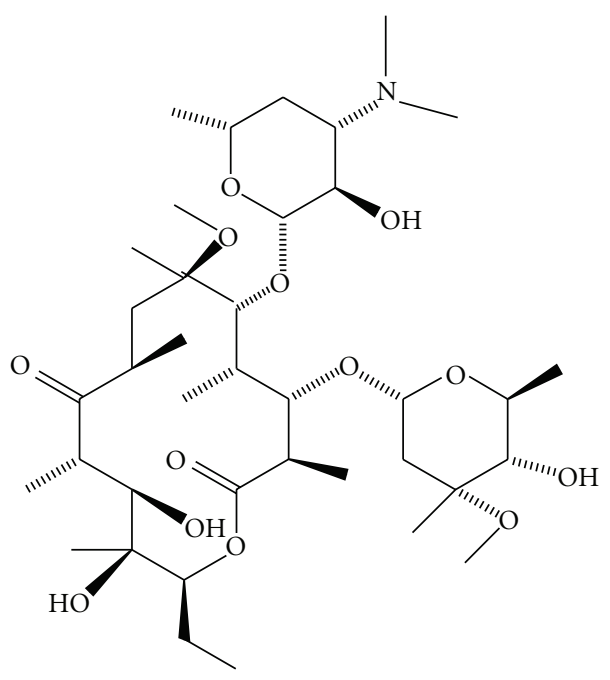

(II)

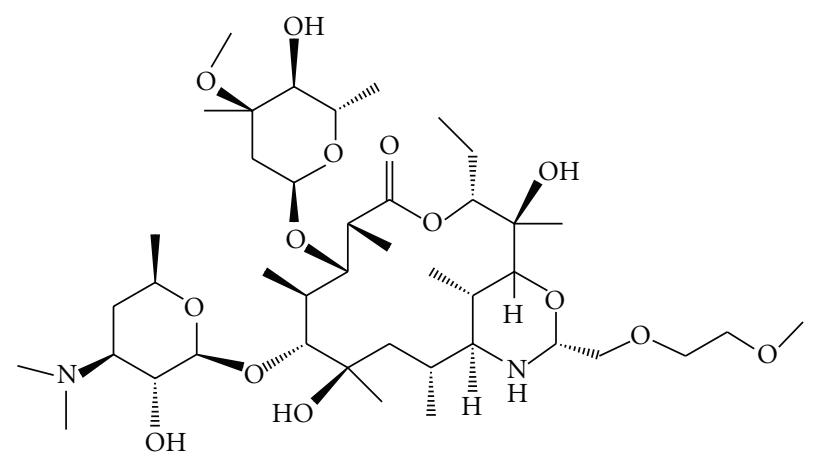

(IV)

FIGURE 1: Chemical structure of 14-membered macrolide antibiotics. (I—Erythromycin, II—Clarithromycin, III-Roxithromycin, IVDirithromycin).

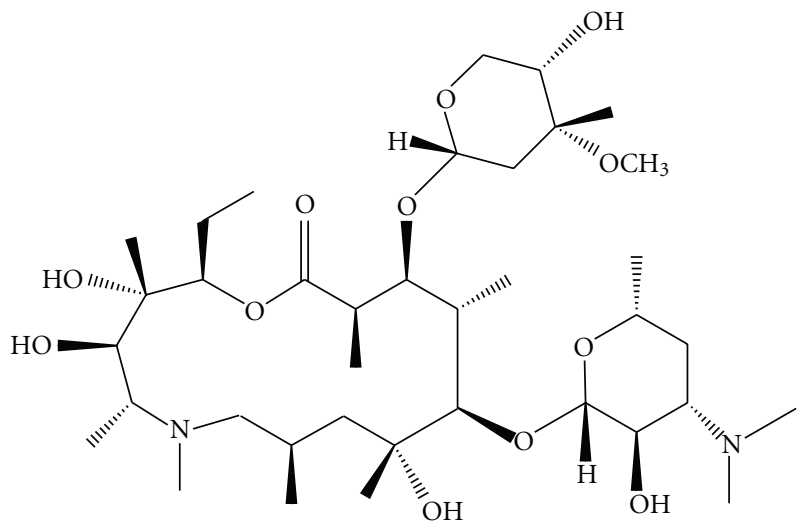

FIGURE 2: Chemical structure of azithromycin. except azithromycin on stimulation of macrophage functions have been described [12]. Several small clinical trials have shown that erythromycin, clarithromycin, and azithromycin possess anti-inflammatory characteristics in patients with respiratory diseases. To determine whether macrolide antibiotics possess this unique characteristic, data from controlled trials involving human subjects were extracted and analyzed. Conclusions from trials suggest that the selected macrolide antibiotics possess anti-inflammatory properties in patients with respiratory diseases who do not show evidence of a bacterial infection [13].

1.3. Pharmacokinetics of Macrolide Antibiotics. Erythromycin is easily inactivated by diarrhea; therefore, all orally administered formulations are given as either enteric-coated or 


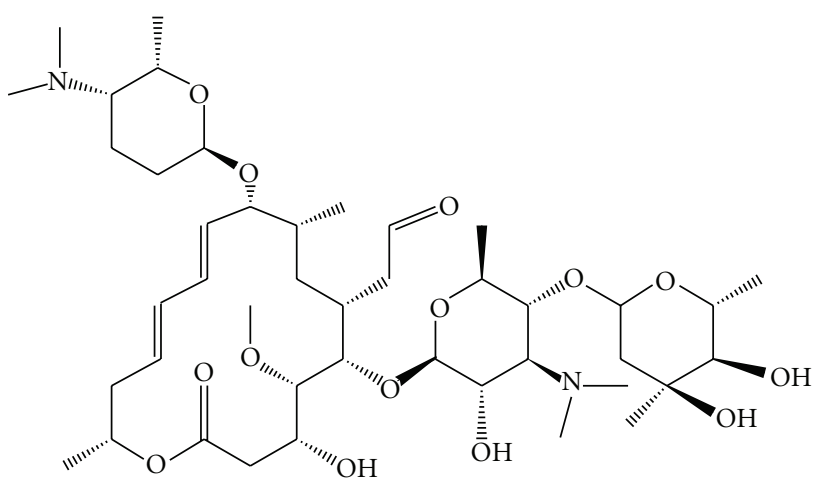

(I)

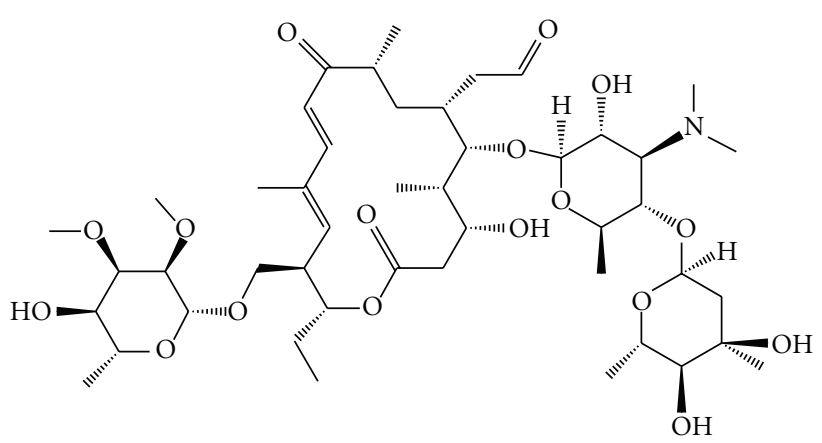

(II)

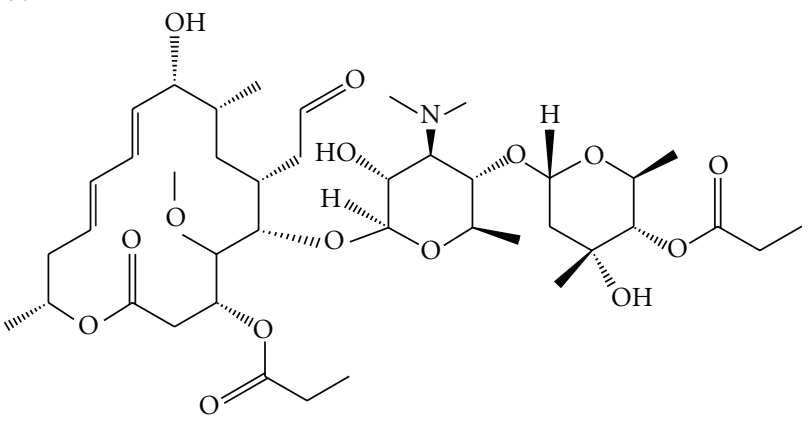

(III)

Figure 3: Chemical structure of 16-membered macrolide antibiotics. (I-Spiramycin, II-Tylosin, III-Midecamycin).

more-stable laxatives or esters, such as erythromycin ethylsuccinate. Erythromycin is very rapidly absorbed and diffuses into most tissues and phagocytes. It is metabolized by demethylation in the liver. Its main elimination route is in the bile, and a small portion in the urine. Erythromycin's elimination half-life is 2.5 hours.

Unlike erythromycin, azithromycin is acid stable and can therefore be taken orally with no need of protection from gastric acids. It is readily absorbed and diffused into most tissues and phagocytes. The concentration of azithromycin in the tissues can be 50 times higher than in plasma. This is due to ion trapping and the high lipid solubility.

Following a single $500 \mathrm{mg}$ dose, plasma concentrations of azithromycin declined in a polyphasic pattern with a mean apparent plasma clearance of $630 \mathrm{~mL} / \mathrm{min}$ and a terminal elimination half-life of 68 hours. Prolonged terminal halflife is thought to be due to extensive uptake and subsequent release of drug from tissues.

Biliary excretion of azithromycin, predominantly unchanged, is a major route of elimination. Over the course of a week, approximately $6 \%$ of the administered dose appears as unchanged drug in urine.

When taken before a meal, roxithromycin is very rapidly absorbed and diffused into most tissues and phagocytes. Only a small portion of roxithromycin is metabolized. Most of roxithromycin is secreted unchanged into the bile and some in expired air. Less than $10 \%$ is excreted into the urine. Roxithromycin's half-life is 12 hours.
1.4. Physicochemical Properties of Macrolides. Macrolide antibiotics are structurally characterized by four common moieties: the presence of a large lactone ring, a ketone group, a glycosidically linked amino sugar attached either to amino sugar or to nucleus, and dimethylamino moiety on the sugar residue, which makes the antibiotics basic [14]. PKa values of most macrolides ranged between 6.0 and 9.0 and afford the possibility of preparing their clinically useful salts [15]. They are generally nonpolar and almost insoluble in water.

Erythromycin occurs as white or slightly yellow, odorless or almost odorless, slightly hygroscopic, crystals, or powder. Unlike azithromycin, erythromycin has a higher melting point, $135-140^{\circ} \mathrm{C}$. It is optically active with $[\alpha]^{25}$ of $-78^{\circ}$ at concentration of $0.0199 \mathrm{mg} \mathrm{mL}^{-1}$ in methanol. It exhibits characteristic UV absorption maxima when dissolved in water $(\mathrm{pH} 6.3)$ at $280 \mathrm{~nm}(\varepsilon=50)$. The $\mathrm{pKa}$ value is higher than azithromycin (8.8), but the solubility profile is similar with that of azithromycin [16].

Azithromycin has a melting point of $113-115^{\circ} \mathrm{C}$. It is levorotatory with $[\alpha]^{25}$ D of $-37^{\circ}$ at concentration of $0.01 \mathrm{mg} \mathrm{mL}^{-1}$ in chloroform. It has no characteristic UV absorption maximum in any solvent. It has a pKa value of 7.9. The solubility of azithromycin in water is $2 \mathrm{mg} \mathrm{L}^{-1}$. It is, however, freely soluble in alcohols, acetone, chloroform, acetonitrile, and ethyl acetate and moderately soluble in ether, ethylene chloride, and amyl acetate.

Clarithromycin exhibits a higher melting point, 217$220^{\circ} \mathrm{C}$, and it is levorotatory with $[\alpha]^{25} \mathrm{D}$ of $-90.4^{\circ}$ at 
concentration of $1 \mathrm{mg} / \mathrm{mL}$ in chloroform. Its UV-spectrum in chloroform exhibits absorbance maxima at $288 \mathrm{~nm}(\varepsilon=$ 27.9) and the solubility profile is like azithromycin [17].

Tylosin is an almost white or slightly yellow crystalline powder, with melting point $128-132^{\circ} \mathrm{C}$. It is also soluble in water $\left(5 \mathrm{mg} \mathrm{mL}^{-1}\right.$ at $\left.25^{\circ} \mathrm{C}\right)$. However, it is lower soluble in alcohols, esters, ketones, benzene, ether, and chloroform. It has a pKa value of 7.73 and UV absorption maxima at $282 \mathrm{~nm}$ with extinction coefficient (E1cm, 1\%) 245.

\section{Analytical Techniques for the Determinationnewline of Macrolide Antibiotics}

Determination of antibiotics, including macrolides, is mainly carried out by microbiological assays. However, the assays tended to lack specificity. And hence to overcome this problem, lots of chemical and instrumental methods have been developed in different times by different researchers to determine these macrolides separately as well as simultaneously. These methods that have been developed to analyze macrolides include chromatographic methods, spectrophotometric methods, and electrochemical methods.

\subsection{Chromatographic Techniques}

2.1.1. Thin Layer Chromatography and Paper Chromatography. Thin layer chromatography is one of the most important technique for qualitative and semiquantitative analysis of drugs in bulky powders, dosage forms, and body fluids. Drug screening TLC methods are simple, inexpensive, selective, and semiquantitative, and they can be used in the laboratory or in the field in locations such as a port of entry, distribution center, clinic, pharmacy, or hospital. TLC can give an indication whether the active ingredient is present and its level of content and, therefore the product is qualified or authorized in this basis. Some related substances may also be detected and quantified. However, TLC will not detect counterfeits that have wrong active or inactive ingredients if they are not visualized by the detection method being used for the correct active drug [18].

Initial attempts to analyze erythromycin involved the use of TLC to separate erythromycin A and erythromycin B, pseudoerythromycin A enol ether, and anhydroerythromycin. Separation was effected on silica-gel TLC plates using various mixtures of organic solvents and the relevant compounds visualized by spraying with $50 \%$ aqueous sulfuric acid and charring. Visualization spray consisting of cerium sulfate (1\%) and molybdic acid (2.5\%) in $10 \%$ sulfuric acid has also been used [19]. TLC on silica gel followed by densitometry has been applied to separate erythromycin base and erythromycin estolate in capsules [20]. The separation of erythromycin from erythromycin stearate tablets and erythromycin estolate suspensions by TLC on silica gel was reported in 1976 [21]. Kibwage et al. [22] separated erythromycin A, erythromycin B, erythromycin C, and erythromycin D using TLC coated with Kieselgel GF254 and sprayed with a mixture of anisaldehyde-sulfuric acidethanol $(1: 1: 9)$ and heated.

A TLC method for the separation of erythromycin, tylosin, oleandomycin, and spiramycin in livestock products has also been reported [23]. The plates were sprayed with xanthydrol and heated at $110^{\circ} \mathrm{C}$ for $5 \mathrm{~min}$. Semiquantitative analysis was carried out by densitometry scanning at $525 \mathrm{~nm}$. Flurithromycin is a novel macrolide antibiotic used as the ethylsuccinate salt. Colombo et al. [24] reported TLC systems for the chromatographic identification, quantitation, and subsequent structural identification of flurithromycin ethylsuccinate. Separation by TLC was effected and the spots were visualised by exposure to iodine vapor or by spraying with an anisaldehyde-sulfuric acid-glacial acetic acid-methanol mixture and warming.

Lees et al. [25] described the use of a paper chromatographic analysis for the separation of the acetylated oleandomycins in multicomponent antibiotic mixtures. Highpolar solvent systems were found to be suitable for the separation of oleandomycin base and its acetylated derivatives, including triacetyl-oleandomycin. In addition, the effects of $\mathrm{pH}$ of the paper and of the solvent system on the chromatographic separation of magnamycin, erythromycin stearate, oleandomycin phosphate, picromycin, and methymycin were investigated. Different researches have shown that the use of buffered solvents completely eliminated the tailing of spots and so that the evaluation of the spot would very precise and accurate.

The use of High Performance Thin Layer Chromatography in the analysis of some sixteen-membered ring macrolide antibiotics like Spiramycins, Tylosins, Turimycins, and 9Propionyl maridomycins was examined by Bens et al. (1980). In the case of Spiramycins, instrumentalized HPTLC proved to be very efficient for the separation and determination of these antibiotics. With the use of an internal standard together with the data pair technique in sampling and evaluation of the HPTLC plates, a coefficient of variation less than $1.5 \%$ could be achieved when determining the different Spiramycins. Other sixteen-membered macrolides, such as Tylosins, Turimycins, and 9-Propionylmaridomycins can be separated with sufficient resolution for quantitative work, in spite of their extremely similar structures and large molecular weights. Detection is always at wavelengths, which agree with the intrinsic absorption maximum of the chromophors of the components (e.g., $282 \mathrm{~nm}$ for Tylosins, $232 \mathrm{~nm}$ for Spiramycins and Turimycins, and $195 \mathrm{~nm}$ for 9Propionylmaridomycins) [26].

2.1.2. Gas Chromatography. Gas-liquid chromatography has been used for the quantitative analysis and separation of erythromycin in mixtures containing erythromycin $\mathrm{A}$, erythromycin B, erythromycin C, erythrolosamine, and propionyl erythromycin using flame-ionization detection. Similarly, erythromycin A and erythromycin B were separated and quantitated in the presence of erythromycin $\mathrm{C}$ and erythrolosamine in erythromycin tablets [27]. A procedure for the qualitative identification of erythromycin in erythromycin ethyl succinate capsules using pyrolysis-gas chromatography has also been reported [28]. 
2.1.3. High-Performance Liquid Chromatography. An early report describing the application of liquid chromatography for the analysis of erythromycin A, erythromycin B, and leucomycins was published in 1973 [29]. Erythromycin has a low molar absorptivity as it lacks a suitable chromophore. Thus, specific, selective, and sensitive UV detection of this compound is difficult. To overcome this problem, low UV wavelength, where considerable UV absorption occurs, has been used. This generally necessitates the use of extensive precolumn extraction procedures in order to eliminate potentially interfering components, particularly when using complex matrices such as biological fluids and tissues. Generally, a wavelength of $215 \mathrm{~nm}$ has proved to be the most useful wavelength to monitor erythromycin and related compounds and has been extensively used in most applications.

An HPLC method for the simultaneous determination of five macrolides (josamycin, kitasamycin, mirosamicin, spiramycin, and tylosin) in meat has been reported. The drugs were extracted with $0.3 \%$ metaphosphoric acidmethanol $(7: 3, \mathrm{v} / \mathrm{v})$, and the extracts were cleaned up on a Bond Elut SCX cartridge. The HPLC separation was performed on octadecyl analytical column with a gradient system of $0.025 \mathrm{M}$ phosphate buffer ( $\mathrm{pH} 2.5$ ) and acetonitrile as the mobile phase. The drugs were detected at $232 \mathrm{~nm}$ for josamycin, kitasamycin, mirosamicin, and spiramycin, and $287 \mathrm{~nm}$ for tylosin [30].

HPLC with ultraviolet detection has been used for the analysis of azithromycin in bulk samples, for the separation of related compounds produced during synthesis, and for acid degradation studies. Methods for the HPLC analysis of azithromycin in biological samples have also been described using various methods of detection in order to overcome the limitations of poor UV absorbance. Shepard et al. [31] used both coulometric and amperometric methods for the detection of azithromycin in human and animal tissues and serum.

Like erythromycin, clarithromycin has no conjugated double bond in the lactone ring; hence significant UV absorbance is only obtained at wavelengths below $210 \mathrm{~nm}$. Whilst UV detection of clarithromycin may be suitable for most in vitro samples, electrochemical detection has proved to be most effective when quantitation of low concentrations of the drug in biological samples is required. Morgan et al. [32], using reversed-phase chromatography at $50^{\circ} \mathrm{C}$ with UV detection, were able to separate clarithromycin and eight related compounds produced during the synthetic process. They found that separation was largely dependent on the organic-aqueous ratio of the mobile phase and, in contrast to erythromycin, almost unaffected by temperature and $\mathrm{pH}$, although an elevated column temperature was used to maintain peak symmetry and resolution.

Torano and Guchelaar (1998) have reported an HPLC method for the determination of erythromycin, azithromycin, clarithromycin, and roxithromycin in human serum. A diethyl ether extract, obtained from serum using a saturated sodium carbonate solution, was treated with 9-fluorenylmethyl-oxycarbonyl chloride for $40 \mathrm{~min}$ at $40^{\circ} \mathrm{C}$ and chromatographed on a base-deactivated octadecyl column, maintained at $50^{\circ} \mathrm{C}$ during elution, using an eluent composed of acetonitrile-hydrogenphosphate buffer, $\mathrm{pH} 7.5$, with $0.125 \%$ triethylamine $(3: 2, \mathrm{v} / \mathrm{v})$. Fluorescence detection was used at an excitation wavelength of $255 \mathrm{~nm}$ and an emission wavelength of $315 \mathrm{~nm}$ [33].

An HPLC method with fluorescence detection for the determination of roxithromycin in human plasma was described by Owka and Karazniewicz-lada (2007). After solid-phase extraction, roxithromycin and erythromycin (as internal standard) were derivatized by treatment with 9fluorenylmethyl chloroformate. Optimal resolution of fluorescence derivatives of roxithromycin and the internal standard was obtained using reversed phase, C18 column. The mobile phase was composed of potassium dihydrogenphosphate solution, $\mathrm{pH} 7.5$, and acetonitrile. Fluorescence of the compounds was measured at the maximum excitation, $255 \mathrm{~nm}$ and emission, $313 \mathrm{~nm}$, of roxithromycin derivatives. The method has been validated and would be successfully applied for pharmacokinetic studies of roxithromycin after administration of a single tablet of roxithromycin [34].

In 2000, Gandhi et al. [35] described an HPLC method using amperometric detection for the analysis of azithromycin that is, for assay and dissolution test in different dosage forms. Patricia Zubata et al. (2002) have utilized HPLC techniques for the determination of azithromycin in bulky powder and different dosage forms. The authors have described that the use of reversed phase chromatographic conditions at $215 \mathrm{~nm}$ detection is the most optimized method and gave accurate and precise results [36].

Macrolide antibiotics, which have veterinary application like spiramycin, tilmicosin, and tylosin, can be determined from food of animal origin, like meat, liver, kidneys, raw milk, and eggs by HPLC method. The method is based on a solid phase extraction clean-up with a cation exchange cartridge and a separation by liquid chromatography with UV detection. The author has described that the selectivity of the method is very good, and no interfering peaks are observed for various food matrices [37].

Chen et al. (2006) have described the application of liquid chromatography with mass spectrometric detection. As the authors have revealed, azithromycin was extracted from plasma with methyl tert-butyl ether-hexane (50:50, $\mathrm{v} / \mathrm{v})$. The organic phase was evaporated to dryness at $40^{\circ} \mathrm{C}$ and dissolved in mobile phase. The separation was carried out on a reversed-phase octadecyl analytical column with a mobile phase containing of $20 \mathrm{mM}$ ammonium acetate$(\mathrm{pH} 5.2)$ acetonitrile-methanol $(50: 40: 10, \mathrm{v} / \mathrm{v} / \mathrm{v})$ at a flow rate of $0.2 \mathrm{~mL} / \mathrm{min}$. Azithromycin and its internal standard, clarithromycin, were measured by electro-spray ion source in positive selective ion monitoring mode. The limit of quantification for azithromycin in plasma was $2 \mathrm{ng} \mathrm{mL}^{-1}$ with good accuracy and precision. The authors have applied the established method to bioequivalence study of azithromycin in two formulations [38].

Another electrospray high-performance liquid chromatographic tandem mass spectrometric (HPLC-MS-MS) method capable of determining the following five macrolides: tylosin, tilmicosin, spiramycin, josamycin, erythromycin in several tissues (muscle, kidney, liver), eggs, and milk has 
been presented by Dubois et al. (2001). In this method, roxithromycin was used as an internal standard. The method uses extraction in a Tris buffer at $\mathrm{pH} 10.5$, followed by protein precipitation with sodium tungstate and clean-up on a solid-phase extraction column. The HPLC separation was performed on an octadecyl analytical column protected by a guard column, with a gradient of aqueous $0.1 \mathrm{M}$ ammonium acetate-acetonitrile as the mobile phase [39].

USP and BP are also mentioned in this technique to be used for the analysis of certain types of macrolide antibiotics. For example, the analysis of erythromycin tablet and erythromycin lactobionate intravenous injections by using HPLC has been stated in BP. Similarly, clarithromycin (raw material, oral suspension, and tablet), azithromycin (raw material, capsule, and oral suspension), dirithromycin (raw material, and delayed release tablet), erythromycin raw material and content of tylosins can be analyzed by the use of HPLC as stated in the USP $[16,40]$.

Different Chromatographic Conditions Stated in Official Monographs and Some Published Literatures for the Analysis of macrolide antibiotics in different formulations and biological matrices are summarized in Tables 1 and 2, respectively.

2.1.4. Capillary Electrophoresis. The advent of capillary electrophoresis and its application for the separation and quantitative analysis of drugs and mixtures thereof will undoubtedly make a significant impact as yet another important analytical procedure. Although capillary electrophoresis has already been successfully applied to analyze many drugs, only a few publications to-date have been reported using this technique for the separation and quantitation of erythromycin. The method of Flurer [50] described methods to study various mixtures of macrolide antibiotics. Selected macrolides were analyzed by capillary electrophoresis in two separation schemes. Both systems separated oleandomycin from its triacetate derivative, troleandomycin, and erythromycin from some of its derivatives. Lalloo and Kanfer have described the development of capillary elecrophoresis method for the separation of erythromycin, josamycin, and oleandomycin, and a subsequent paper by the same authors describes the same technique for the quantitative determination of erythromycin and related substances [51].

Capillary electrophoresis was utilized in the analysis of macrolide antibiotics like clarithromycin, erythromycin, oleandomycin, troleandomycin, and spiramycin. In order to assist in analyte solubilization, two buffer systems using acetonitrile were developed. The first system involved $30 \mathrm{mM}$ sodium cholate and $20 \%$ acetonitrile in $80 \mathrm{mM}$ sodium phosphate, $\mathrm{pH}$ 6. This buffer permitted the baseline resolution of all five glycoconjugated antibiotics. In addition, erythromycin was separated from its derivatives estolate and ethylsuccinate. In the absence of surfactants, a higher acetonitrile quantity, 65\%, was used in the second buffer system, with $35 \mathrm{mM}$ sodium phosphate, $\mathrm{pH}$ 6. Selectivity between oleandomycin and clarithromycin was reversed in this system compared to the cholate buffer, indicating solute interaction with the cholate micelles in the previous system. Calibration linearity and detection sensitivity were improved in the high acetonitrile buffer, due to decreased background absorbance. It was demonstrated that both buffer systems can be utilized for the visualization of minor components that may be present in bulk pharmaceuticals [42].

\subsection{Spectrophotometric Techniques. Macrolide antibiotics do} not have sufficient chromophoric groups, which enable this group of compound to be determined directly by spectrophotometer. They absorb at shorter wavelengths at which more interference exist. And hence it is necessary to derivative or make complex of these compounds to colored product to be determined spectrophotometrically. Spectrophotometer is an important detector, which is widely used with HPLC and HPTLC for the detection of macrolide antibiotics

2.2.1. Absorption Spectrophotometric Methods. Erythromycin has been analyzed by UV-Vis spectrophotometric methods based on reaction with an acidic dye, concentrated sulphuric acid, and ferric ions or on the formation of blue-colored complex with gentian violet at $633 \mathrm{~nm}$.

Erythromycin, azithromycin dihydrate, clarithromycin, and roxithromycin have been determined in bulk powders, pharmaceutical formulations, and spiked biological fluids by formation of a binary complex between each of these drugs and eosin $\mathrm{Y}$ in aqueous-buffered medium. The binary complexes showed absorption maxima at $542-544 \mathrm{~nm}$. The absorbance of the binary complexes obeyed Beer's law over the concentration range of $1-10 \mu \mathrm{g} \mathrm{mL}^{-1}$ for azithromycin, $2-20 \mu \mathrm{g} \mathrm{mL}^{-1}$ for erythromycin and roxithromycin, and 3$30 \mu \mathrm{g} \mathrm{mL}^{-1}$ for clarithromycin. The limit of detection for erythromycin and azithromycin is $2 \times 10^{-7}, 4 \times 10^{-7}$ for clarithromycin, and $3 \times 10^{-7}$ molar for roxithromycin [52]. Roxithromycin has been also analyzed by spectrophotometric methods based on either ion-pair formation or on reaction with vanillin and p-dimethylaminobenzaldehyde. Spectrophotometric quantitation of erythromycin, oleandomycin, troleandomycin, spiramycin, and tylosin after reaction with concentrated sulphuric acid is studied at about $470 \mathrm{~nm}$ by Danielson et al. As the author revealed, the sugar moieties of the antibiotics are the reactive sites for this method and the detection limits are about $0.2-1.0 \mu \mathrm{g} \mathrm{m}^{-1}$ [53].

Azithromycin can be analyzed spectrophotometrically based on the formation of an ion pair between it and an inorganic complex of $(\mathrm{Mo}(\mathrm{V})$-thiocyanate) followed by its extraction with dichloroethane. This ion-association complex shows an orange color and exhibits a maximum absorbance at $469 \mathrm{~nm}$. The method obeyed beers-Lambert law in the range of $10^{-6}$ to $10^{-5} \mathrm{M}$ of Azithromycin. As the author described, the method has been successfully applied to the determination of azithromycin in pharmaceutical formulations without getting any interference from the common excipients present in azithromycin formulations. Furthermore, this spectrophotometric method has been applied successfully to illustrate the dissolution profiles of original tablets and generic compounds; hence, it could 


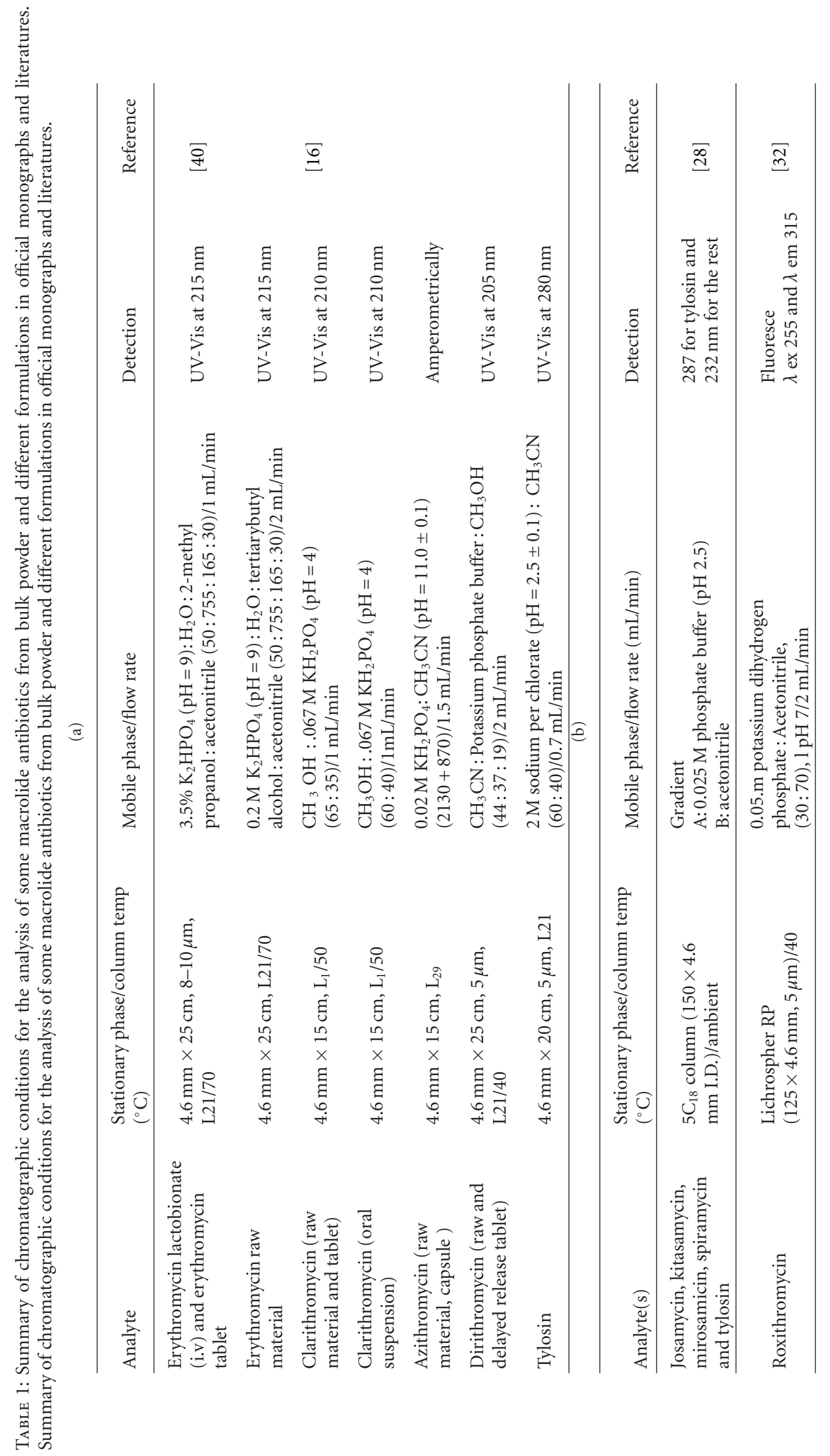




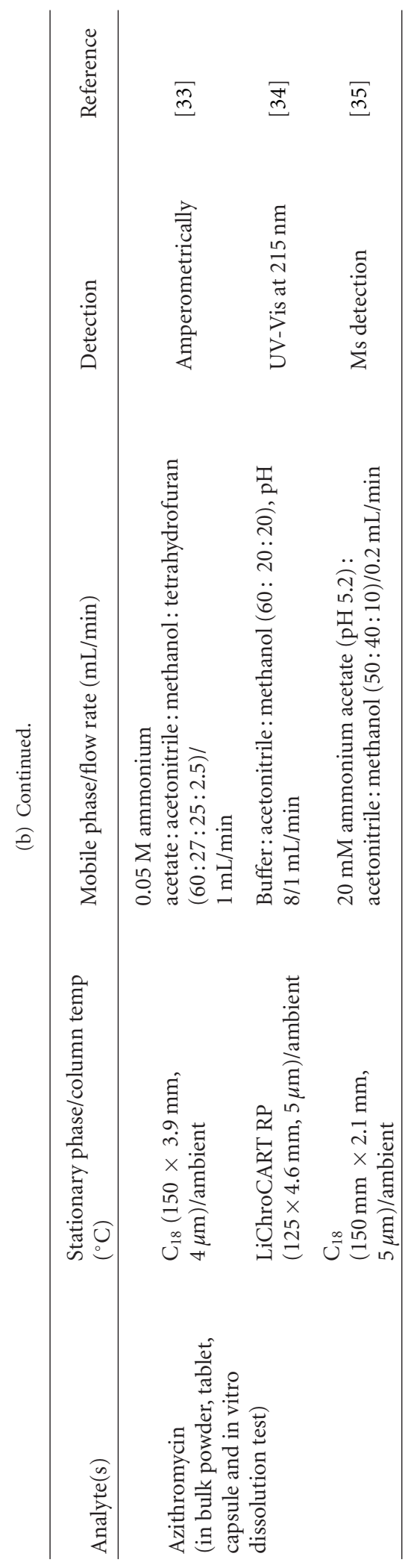




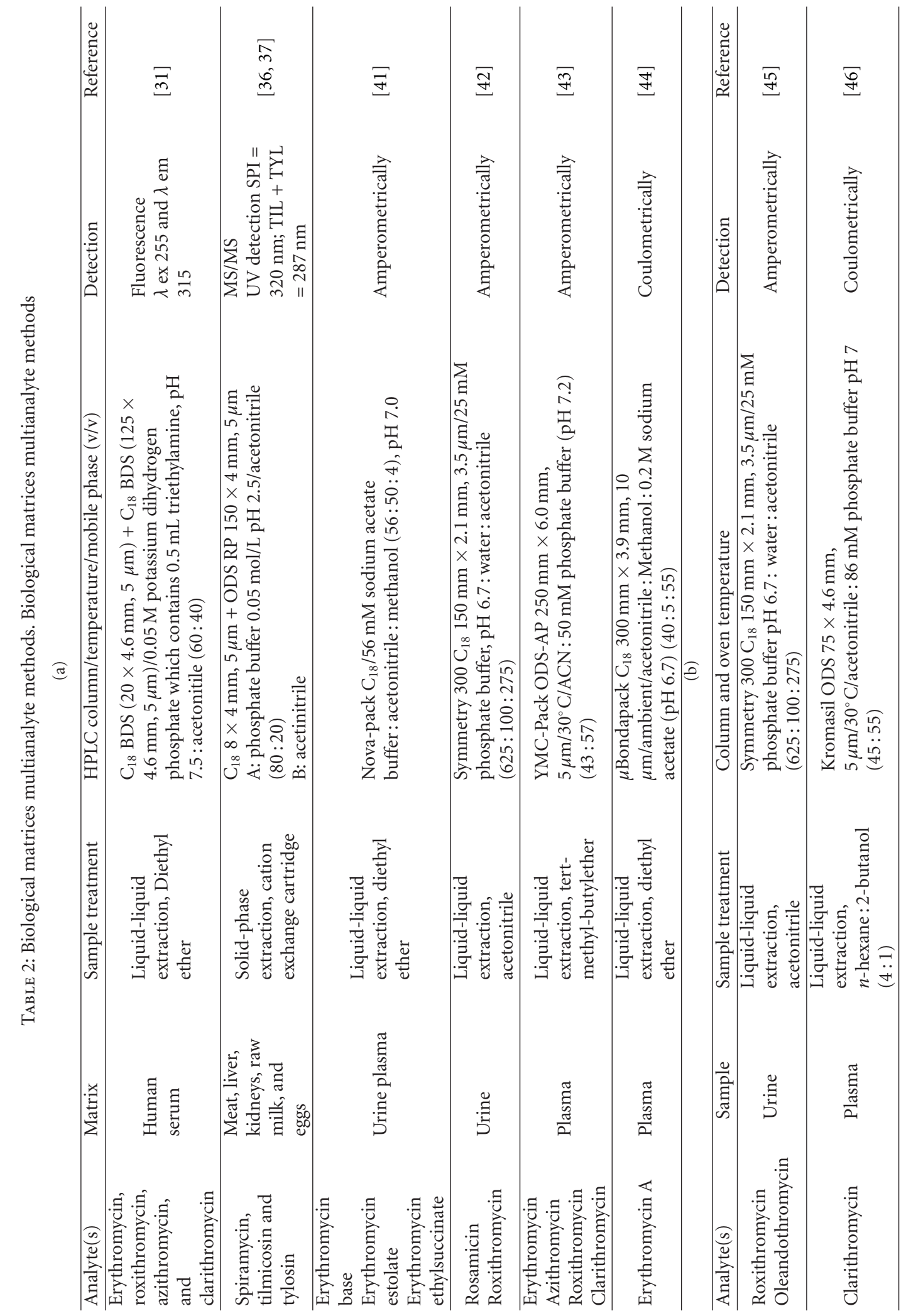




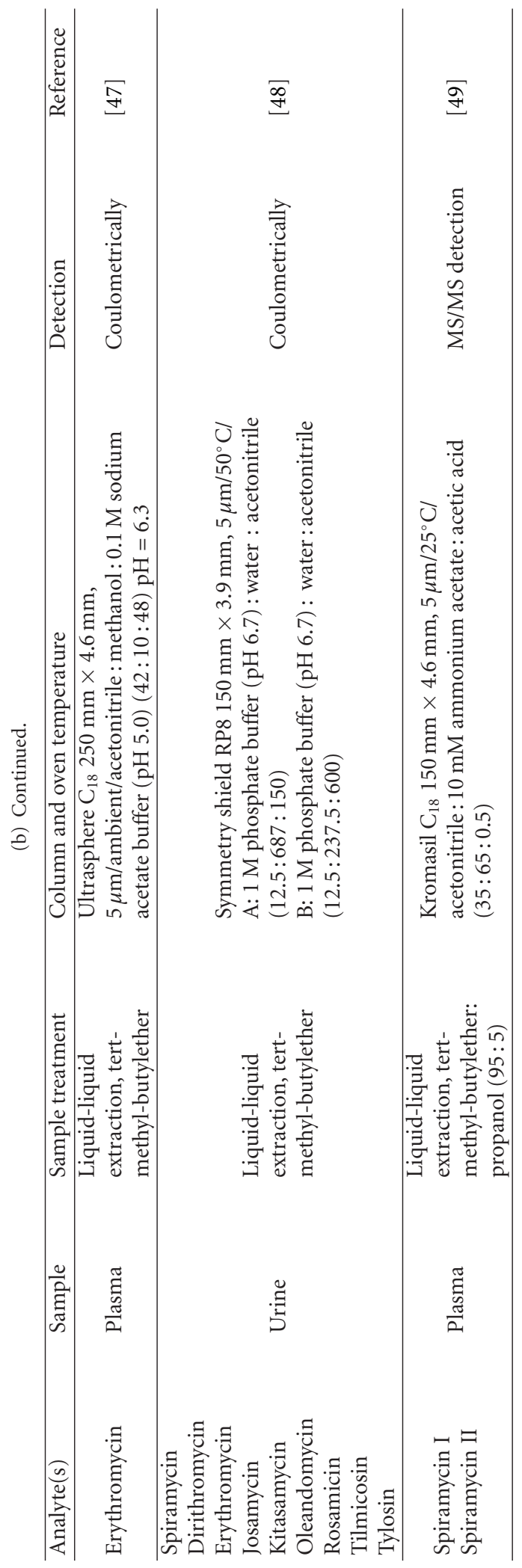


be employed in routine quality control of azithromycin in pharmaceutical dosage forms [54].

Al-Majed et al. (2004) have presented a spectrophotometric method for the determination of josamycin in its dosage forms and spiked human plasma. The method is based on reaction of the drug with 3-methylbenzothiazolin2-one hydrazone/ferric chloride system for a fixed time of 20 minutes at $70^{\circ} \mathrm{C}$ and measuring the intensity of the produced color at $665 \mathrm{~nm}$. The absorbance-concentration plot is linear over the range of $5.0-30.0 \mu \mathrm{g} \mathrm{mL}^{-1}$ with detection limit of $1.0 \mu \mathrm{g} \mathrm{mL}^{-1}$ [55].

2.2.2. Spectrofluorimetric Methods. Erythromycin can be determined by spectrofluorimetric methods using erythrosine $\mathrm{B}$, or napthotriazole disulfonate as a derivatizing reagent. The macrolides (erythromycin, erythromycin esters, azithromycin dihydrate, clarithromycin, and roxithromycin) can be analyzed by a simple spectrofluorimetric method based on the oxidation of these drugs by cerium (VI) in the presence of sulphuric acid and monitoring the fluorescence of cerium (III) formed at $\lambda_{\text {ex }} 255 \mathrm{~nm}$ and $\lambda_{\text {em }} 348 \mathrm{~nm}$. Linear calibration graphs were obtained in the range of $42.6-1200 \mathrm{ng} \mathrm{mL}^{-1}$. The method was applied successfully for the assay of the studied drugs in pure and pharmaceutical dosage forms as tablets, capsules, and suspension without being affected by the potential interference of excipients like glucose, sucrose, lactose, citric acid, and propylene glycol [56].

El-Rabbat et al. have described a simple spectrofluorometric method for the analysis of 4 macrolide antibiotics. The method is based on the condensation of $10 \%$ $(\mathrm{w} / \mathrm{v})$ malonic acid and acetic acid anhydride under the catalytic effect of tertiary amine groups of the studied macrolides. The relative fluorescence intensity of the condensation product was measured at 397/452 nm (excitation/ emission) for azithromycin dihydrate and at $392 / 445 \mathrm{~nm}$ for clarithromycin, erythromycin ethylsuccinate, and roxithromycin. The effects of potential interference due to common excipients, such as starch, lactose, sucrose, glucose, gum acacia, and magnesium stearate, as well as trimethoprim and sulfisoxazole acetyl formulated in primomycin capsules and pediazole oral suspension, respectively, were studied. The linearity ranges were $3-80 \mathrm{ng} \mathrm{mL}^{-1}$ for all of the cited macrolides. The limit of detection range was $0.74-1.20 \mathrm{ng}$ $\mathrm{mL}^{-1}$, while the limit of quantitation range was $2.47-$ $4.02 \mathrm{ng} \mathrm{mL}^{-1}$. The method was applied for the assay of the studied macrolides in pure pharmaceutical formulations and in spiked biological fluids [57].

2.3. Electrochemical Techniques. Electrochemical techniques like amperometric, voltammetric, and coulometric are widely used as detector for sophisticated analytical instruments like high performance liquid chromatography and capillary electrophoresis. Since these techniques are highly sensitive, they can be commonly utilized for the determination of macrolide antibiotics from biological matrices.

The oxidative behavior of azithromycin was studied at glassy carbon electrode in different buffer system using cyclic, linear sweep and differential pulse voltammetry. The oxidation process was shown to be irreversible over the entire $\mathrm{pH}$ range studied (5-11) and was diffusion/adsorption controlled. Analytical method with adequate precision and accuracy was developed for the determination of azithromycin in phosphate buffer at $\mathrm{pH} 7$ as supporting electrolyte containing $10 \%$ methanol and $0.05 \mathrm{M}$ ammonium acetate. The peak current varied linearly with azithromycin concentration in the range $1-15 \mathrm{mg} \mathrm{mL}^{-1}$. The method was successfully applied for assay of the drug in the pharmaceutical dosage forms.

Of the different functional groups of azithromycin, the amine group is the most easily oxidizable. Dialkylamines are oxidized forming a radical cation by loss of one electron. The similar voltammetric behaviour of structurally analogous drug, erythromycin, indicates that the mechanism proposed for the anodic oxidation of azithromycin is initiated by oneelectron transfer to form the cation radical at nitrogen on the desosamine sugar residue [58]. In cyclic voltammograms, one well-defined anodic peak was observed. The fact that no peak was observed in the reverse scan suggests that the oxidation process is an irreversible one. The peak currents decrease with succeeding potential scans suggesting an adsorbed species formation on the electrode surface.

The voltammetric behaviour of josamycin has been studied using direct current, alternating current and differential pulse polarography by Belal et al. 2002. In Britton-Robinson buffers, josamycin developed cathodic waves over the $\mathrm{pH}$ range 7-12. At $\mathrm{pH} 10$, a well-defined cathodic wave with diffusion current constant of $1.06 \pm 0.19(n=5)$ was reported. The wave was characterized as being diffusioncontrolled and partially affected by adsorption phenomenon. The current-concentrations plots are linear over the range 10-60 and 6-50 $\mu \mathrm{g} \mathrm{mL}^{-1}$ using direct current mode and differential pulse polarography mode, respectively. The minimum detectability limit was $1.2 \mu \mathrm{g} \mathrm{mL}^{-1}$. The method is applied for the determination of josamycin in human urine besides to pharmaceutical dosage forms especially in tablets [59].

\section{Microbiological Assays}

The potency of an antibiotic is estimated by comparing the inhibition of growth of sensitive microorganisms produced by known concentrations of the antibiotic being examined and a reference substance.

The reference substances used in the assays are substances whose activity has been precisely determined with reference to the corresponding International Standard or International Reference Preparation.

The analysis of macrolide antibiotics can be carried out by microbial assay according to the official monographs of USP and BP. The British pharmacopoeia has indicated the microbial assay for the analysis of erythromycin ethyl succinate (in oral suspension and tablet) and for erythromycin stearate tablet. Similarly, USP has also indicated the use of microbial assay for erythromycin, Erythromycin estolate, erythromycin ethyl succinate, erythromycin stearate, tylosin, and troleandomycin in different formulations. 


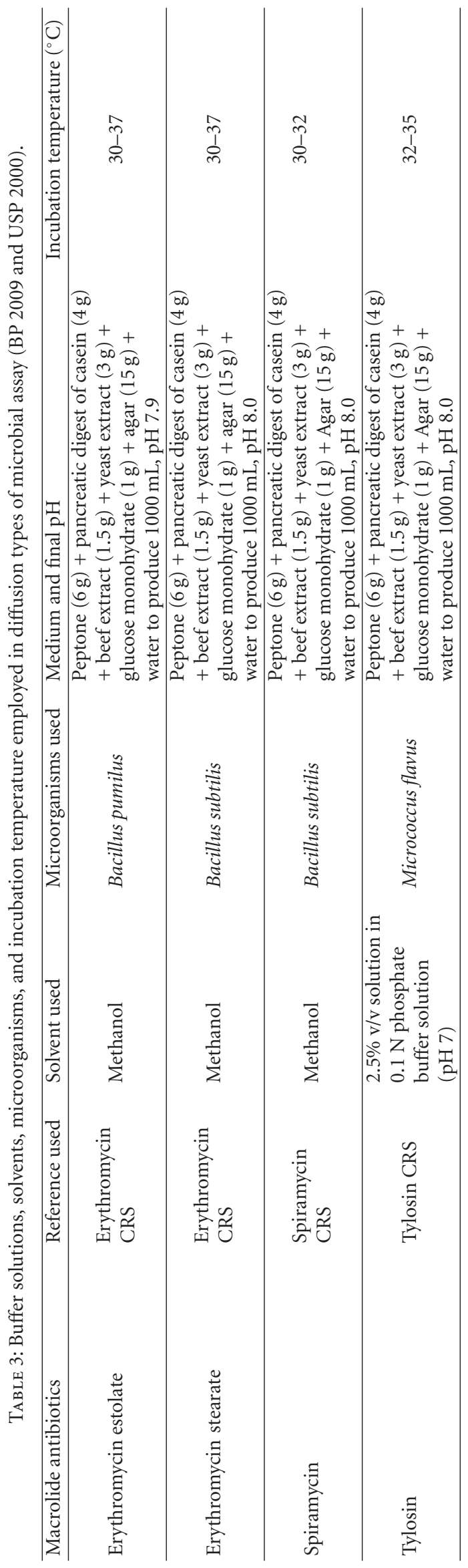




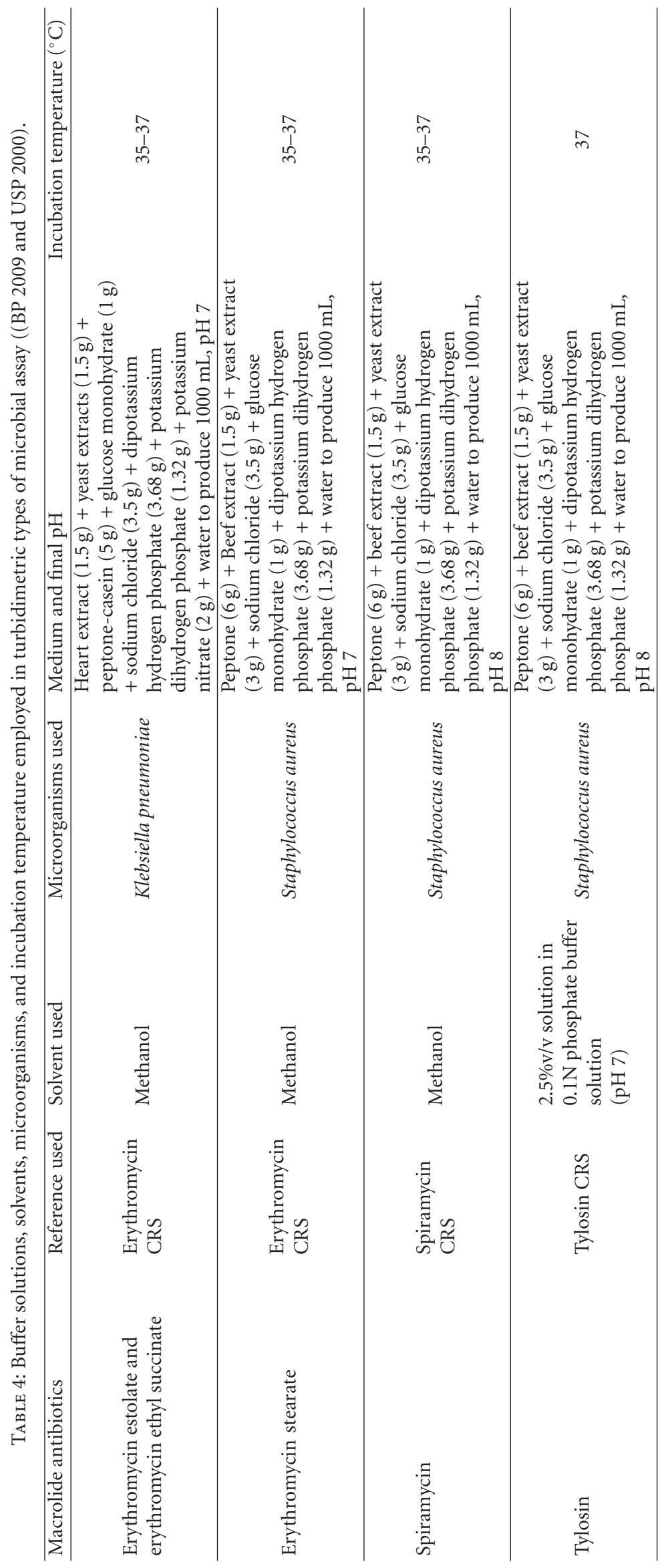


Microbial assay can be carried out either by diffusion or turbid metric method. According to BP, the type of solvent, microorganisms, and medium which have been used for analysis of some macrolide antibiotics using diffusion, and turbidmetric methods have been summarized in Tables 3 and 4.

Turcinov and Pepeljnjak have optimized a microbial diffusion assay method for determination of Azithromycin potency. Measurements $(n=30)$ done on an $8 \times 8$ Latin Square using the group of optimal test microorganisms Bacillus pumilus, Sarcina lutea, and Escherichia coli have confirmed the results of the experiments and their proper selection. According to the authors' description, the above-mentioned microorganisms have produced accurate and precise results for the determination of azithromycin potency. In order to select the most suitable media for each test microorganism in the azithromycin content assay by microbiological diffusion method, different solid media at different $\mathrm{pH}$ were tested. The solid medium, Peptone $6 \mathrm{~g}$, Panc. digest of casein $4 \mathrm{~g}$, Beef extract $1.5 \mathrm{~g}$, Yeast extract $3 \mathrm{~g}$, Glucose $1 \mathrm{~g}$, Agar $15 \mathrm{~g}$ and water to $1000 \mathrm{~mL}$ at $\mathrm{pH} 7.7-7.9$ was found to be the most suitable one for the majority of test microorganisms [60].

\section{Conclusion}

In spite of the great success of HPLC as a valuable tool for the quantitative analysis of macrolide antibiotics, microbiological and nonchromatographic methods are still extensively used. In particular, some official compendia, such as the United States Pharmacopoeia and British pharmacopoeia, retain microbiological assays for the analysis of erythromycin and other macrolide antibiotics. However, HPLC methods have been used for the determination of some newer macrolides, such as clarithromycin, azithromycin, flurithromycin, and dirithromycin.

Several HPLC methods with UV-VIS, fluorescence and mass spectrophotometric detection systems have been employed for the determination of macrolide antibiotics from dosage forms and biological matrices. Few Gas chromatography and capillary electrophoresis methods have been also reported. Spectrophotometric and electrochemical techniques have wide application in the analysis of macrolide antibiotics in bulk powders and different dosage forms.

In general, several analytical techniques for the analysis of macrolide antibiotics have been presented. However, further efforts to use widely modern chromatographic techniques, including $\mathrm{CE}$ and liquid chromatography coupled with tandem mass spectrometry for the quantitative analysis of macrolide antibiotics, will undoubtedly continue. The main goals to be addressed in the future include improved selectivity, sensitivity, analytical simplicity, and efficiency.

\section{References}

[1] K. D. Trigathi, Essentials of Medical Pharmacology, Jaypee Brothers' Medical Publishers, New Delhi, India, 5th edition, 2003.
[2] J. N. Delgado and W. A. Remers, Textbook of Organic Medicinal and Pharmaceutical Chemistry, Lippincott-Raven, Philadelphia, Pa, USA, 10th edition, 1998.

[3] V. T. Andriole, in Proceedings of the 7th Mediterranean Congress on Chemotherapy, Barcelona, Spain, 1990.

[4] L. E. Bermudez, C. Inderlied, and L. S. Young, "Stimulation with cytokines enhances penetration of azithromycin into human macrophages," Antimicrobial Agents and Chemotherapy, vol. 35, no. 12, pp. 2625-2629, 1991.

[5] J. Elks and C. R. Ganellin, Dictionary of Drugs, Chapman and Hall, London, UK, 1991.

[6] S. C. Sweetman, Martindale, the Complete Drug Reference, Pharmaceutical press, London, UK, 33rd edition, 2002.

[7] H. P. Rang, M. M. Dale, J. M. Ritter, and P. K. Moore, Pharmacology, Elsevier, 5th edition, 2003.

[8] S. Omura, Ed., Macrolide Antibiotics: Chemistry, Biology, and Practice, Academic Press, 2nd edition, 2002.

[9] D. A. Williams and T. L. Lenke, Foyes Principle of Medicinal Chemistry, 5th edition, 2008.

[10] B. G. Katzung, Basic and Clinical Pharmacology, 9th edition, 2004.

[11] D. G. Grahame-Smith and J. K. Aronson, Clinical Pharmacology and Therapy, 3rd edition, 1991.

[12] G. Xu, J. Fujita, K. Negayama et al., "Effect of macrolide antibiotics on macrophage functions," Microbiology and Immunology, vol. 40, no. 7, pp. 473-479, 1996.

[13] H. Kourlas, "Anti-inflammatory properties of macrolide antibiotics," Journal of Pharmacy Practice, vol. 19, no. 5, pp. 326-329, 2006.

[14] S. Dokic, G. Kobrehel, G. Lazarevski et al., "Erythromycin series. Part 11. Ring expansion of erythromycin A oxime by the Beckmann rearrangement," Journal of the Chemical Society, Perkin Transactions 1, pp. 1881-1890, 1986.

[15] S. Dokic, G. Kobrehel, N. Lopotar et al., Journal of Chemical Research, vol. 1, pp. 1239-1261, 1988.

[16] The United States Pharmacopoeia/The National Formulary, USP24/NF19, USPConvention Inc., Rockville, Md, USA, pp. 185-187, 424-425, 663-676, 2000.

[17] Clark's Isolation and Identification of Drugs, 5th edition, 1995.

[18] J. Sherma, "Analysis of counterfeit drugs by thin layer chromatography," Acta Chromatographica, no. 19, pp. 5-20, 2007.

[19] A. Banaszek, K. Krowicki, and A. Zamojski, "Thin-layer and column chromatography of erythoromycins andsome degradation products," Journal of Chromatography A, vol. 32, no. C, pp. 581-583, 1968.

[20] C. Radecka, W. L. Wilson, and D. W. Hughes, "Determination of erythromycin in pharmaceutical preparations by direct densitometry after TLC," Journal of Pharmaceutical Sciences, vol. 61, no. 3, pp. 430-431, 1972.

[21] K. C. Graham, W. L. Wilson, and A. Vilim, "Simple thin layer chromatographic identification method for erythromycin stearate," Journal of Chromatography, vol. 125, no. 2, pp. 447450, 1976.

[22] I. O. Kibwage, E. Roets, and J. Hoogmartens, "Thin-layer chromatography of erythromycins and other macrolides," Journal of Chromatography, vol. 256, no. 1, pp. 164-171, 1983.

[23] M. Petz, R. Solly, M. Lymbum, and M. H. Clear, "Thin-layer chromatographic determination of erythromycin and other macrolide antibiotics in livestock products," Journal of The Association of Official Analytical Chemists, vol. 70, no. 4, pp. 691-697, 1987.

[24] N. Colombo, A. Depaoli, M. Gobetti, and M. G. Saorin, "Analytical-physical profile of the novel macrolide antibiotic 
flurithromycin ethylsuccinate," Arzneimittel-Forschung/Drug Research, vol. 44, no. 7, pp. 850-855, 1994.

[25] T. M. Lees, P. J. DeMuria, and W. H. Boegmann, "Paper chromatographic separation of multi-component antibiotic mixtures: the acetylated oleandomycins," Journal of Chromatography A, vol. 5, pp. 126-130, 1961.

[26] G. A. Bens, W. Van den Bossche, and P. de Moerloose, "High performance thin-layer chromatography of some sixteenmembered ring macrolide antibiotics," Journal of High Resolution Chromatography, vol. 3, no. 9, pp. 433-439, 1980.

[27] J. H. Robertson and K. Tsuji, "GLC determination of erythromycin in enteric-coated tablets," Journal of Pharmaceutical Sciences, vol. 61, no. 10, pp. 1633-1635, 1972.

[28] N. D. Danielson, "Simple methods for the qualitative identification and quantitative determination of macrolide antibiotics," Journal of Pharmaceutical and Biomedical Analysis, vol. 11, no. 7, pp. 121-130, 1993.

[29] S. Omura, Y. Suzuki, A. Nakagawa, and T. Hata, "Fast liquid chromatography of macrolide antibiotics," Journal of Antibiotics, vol. 26, no. 12, pp. 794-796, 1973.

[30] M. Horie, K. Saito, R. Ishii, T. Yoshida, Yukari Haramaki, and H. Nakazawa, "Simultaneous determination of five macrolide antibiotics in meat by high-performance liquid chromatography," Journal of Chromatography A, vol. 812, no. 1-2, pp. 295302, 1998.

[31] R. M. Shepard, G. S. Duthu, R. A. Ferraina, and M. A. Mullins, "High-performance liquid chromatographic assay with electrochemical detection for azithromycin in serum and tissues," Journal of Chromatography, vol. 565, no. 1-2, pp. 321337, 1991.

[32] D. Morgan, P. Cugier, B. Marello, C. Sarocka, D. Stroz, and A. Plasz, "Impurity profiling of clarithromycin using high-performance liquid chromatography with ultraviolet detection," Journal of Chromatography, vol. 502, no. 2, pp. 351$358,1990$.

[33] J. S. Torano and H. J. Guchelaar, "Quantitative determination of the macrolide antibiotics erythromycin, roxithromycin, azithromycin and clarithromycin in human serum by high-performance liquid chromatography using pre-column derivatization with 9-fluorenylmethyloxycarbonyl chloride and fluorescence detection," Journal of Chromatography B, vol. 720, no. 1-2, pp. 89-97, 1998.

[34] F. K. G. Owka and M. Karazniewicz-łada, "Determination of roxithromycin in human plasma by HPLC with fluorescence and UV absorbance detection: application of pharmacokinetic study," Journal of Chromatography B, vol. 852, no. 1-2, pp. 669673, 2007.

[35] R. Gandhi, C. L. Kaul, and R. Panchagnula, "Validated LC method for in-vitro analysis of azithromycin using electrochemical detection," Journal of Pharmaceutical and Biomedical Analysis, vol. 23, no. 6, pp. 1073-1078, 2000.

[36] P. Zubata, R. Ceresole, M. A. Rosasco, and M. T. Pizzorno, "A new HPLC method for azithromycin quantitation," Journal of Pharmaceutical and Biomedical Analysis, vol. 27, no. 5, pp. 833-836, 2002.

[37] P. Edder, A. Cominoli, and C. Corvi, Journal of AOACInternational, 1995.

[38] B. M. Chen, Y. Z. Liang, X. Chen, S. G. Liu, F. L. Deng, and P. Zhou, "Quantitative determination of azithromycin in human plasma by liquid chromatography-mass spectrometry and its application in a bioequivalence study," Journal of Pharmaceutical and Biomedical Analysis, vol. 42, no. 4, pp. 480-487, 2006.
[39] M. Dubois, D. Fluchard, E. Sior, and P. Delahaut, "Identification and quantification of five macrolide antibiotics in several tissues, eggs and milk by liquid chromatography-electrospray tandem mass spectrometry," Journal of Chromatography B, vol. 753, no. 2, pp. 189-202, 2001.

[40] British Pharmacopeia, The Staionery Office Limited, vol. 1, pp. 493-494, 742-743, 2004.

[41] D. Croteau, F. Vallée, M. G. Bergeron, and M. LeBel, "Highperformance liquid chromatographic assay of erythromycin and its esters using electrochemical detection," Journal of Chromatography, vol. 419, pp. 205-212, 1987.

[42] M. J. González de la Huebra, G. Bordin, and A. R. Rodríguez, "Development of a multiresidue liquid chromatography method with electrochemical detection (HPLC-ECD) for the determination of macrolide antibiotics," Electroanalysis, vol. 15, no. 5-6, pp. 473-479, 2003.

[43] C. Taninaka, H. Ohtani, E. Hanada, H. Kotaki, H. Sato, and T. Iga, "Determination of erythromycin, clarithromycin, roxithromycin, and azithromycin in plasma by high-performance liquid chromatography with amperometric detection," Journal of Chromatography B, vol. 738, no. 2, pp. 405-411, 2000.

[44] M. L. Chen and W. L. Chou, "Analysis of erythromycin in biological fluids by high-performance liquid chromatography with electrochemical detection," Journal of Chromatography B, vol. 278, pp. 91-100, 1983.

[45] M. J. G. De La Huebra, G. Bordin, and A. R. Rodríguez, "Comparative study of coulometric and amperometric detection for the determination of macrolides in human urine using high-performance liquid chromatography," Analytical and Bioanalytical Chemistry, vol. 375, no. 8, pp. 1031-1037, 2003.

[46] J. I. D. Wobawa, P. N. Shaw, and D. A. Barrett, "Quantification of clarithromycin, its 14-hydroxy and decladinose metabolites in rat plasma, gastric juice and gastric tissue using highperformance liquid chromatography with electrochemical detection," Journal of Chromatography B, vol. 783, no. 2, pp. 359-366, 2003.

[47] S. Laasko, M. Scheinin, and M. Anttila, "Determination of erythromycin base and $2^{\prime}$-acetylerythromycin in human plasma using high-performance liquid chromatography with electrochemical detection," Journal of Chromatography B, vol. 526, pp. 475-486, 1990.

[48] M. J. González de la Huebra, G. Bordin, and A. R. Rodríguez, "A multiresidue method for the simultaneous determination of ten macrolide antibiotics in human urine based on gradient elution liquid chromatography coupled to coulometric detection (HPLC-ECD)," Analytica Chimica Acta, vol. 517, no. 1-2, pp. 53-63, 2004.

[49] D. Zhong, X. Shi, L. Sun, and X. Chen, "Determination of three major components of bitespiramycin and their major active metabolites in rat plasma by liquid chromatographyion trap mass spectrometry," Journal of Chromatography B, vol. 791, no. 1-2, pp. 45-53, 2003.

[50] C. L. Flurer, "Analysis of macrolide antibiotics by capillary electrophoresis," Electrophoresis, vol. 17, no. 2, pp. 359-366, 1996.

[51] A. K. Lalloo and I. Kanfer, "Determination of erythromycin and related substances by capillary electrophoresis," Journal of Chromatography B, vol. 704, no. 1-2, pp. 343-350, 1997.

[52] M. I. Walash, M. S. Rizk, M. I. Eid, and M. E. Fathy, "Spectrophotometric determination of four macrolide antibiotics in pharmaceutical formulations and biological fluids via binary complex formation with eosin and spectrophotometry," Journal of AOAC International, vol. 90, no. 6, pp. 1579-1587, 2007. 
[53] N. D. Danielson, J. A. Holeman, D. C. Bristol, and D. H. Kirzner, "Simple methods for the qualitative identification and quantitative determination of macrolide antibiotics," Journal of Pharmaceutical and Biomedical Analysis, vol. 11, no. 2, pp. 121-130, 1993.

[54] M. Rachidi, J. Elharti, K. Digua, Y. Cherrah, and A. Bouklouze, "New spectrophotometric method for azithromycin determination," Analytical Letters, vol. 39, no. 9, pp. 1917-1926, 2006.

[55] A. A. Al-Majed, F. Belal, N. Y. Khalil, and K. E. E. Ibrahim, "Kinetic spectrophotometric determination of josamycin in formulations and spiked human plasma using 3methylbenzothiazolin-2-one hydrazone/ $\mathrm{Fe}^{+3}$ system," Journal of AOAC International, vol. 87, no. 2, pp. 352-359, 2004.

[56] P. Y. Khashaba, "Spectrofluorimetric analysis of certain macrolide antibiotics in bulk and pharmaceutical formulations," Journal of Pharmaceutical and Biomedical Analysis, vol. 27, no. 6, pp. 923-932, 2002.

[57] N. El-Rabbat, H. F. Askal, P. Y. Khashaba, and N. N. Attia, "A validated spectrofluorometric assay for the determination of certain macrolide antibiotics in pharmaceutical formulations and spiked biological fluids," Journal of AOAC International, vol. 89, no. 5, pp. 1276-1287, 2006.

[58] B. Nigovic and B. Simunic, "Voltammetric assay of azithromycin in pharmaceutical dosage forms," Journal of Pharmaceutical and Biomedical Analysis, vol. 32, pp. 197-202, 2003.

[59] F. Belal, A. Al-Majed, K. E. E. Ibrahim, and N. Y. Khalil, "Voltammetric determination of josamycin (a macrolide antibiotic) in dosage forms and spiked human urine," Journal of Pharmaceutical and Biomedical Analysis, vol. 30, no. 3, pp. 705-713, 2002.

[60] T. Turcinov and S. Pepeljnjak, "Azithromycin potency determination: optimal conditions for microbiological diffusion method assay," Journal of Pharmaceutical and Biomedical Analysis, vol. 17, no. 4-5, pp. 903-910, 1998. 


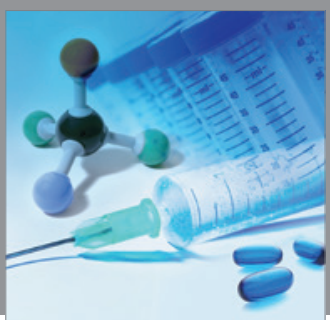

International Journal of

Medicinal Chemistry

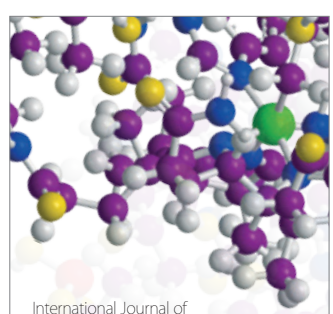

Carbohydrate Chemistry

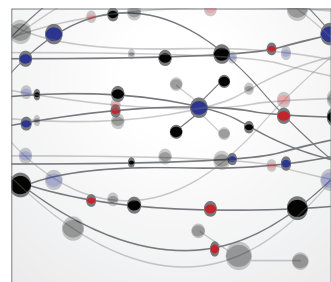

The Scientific World Journal
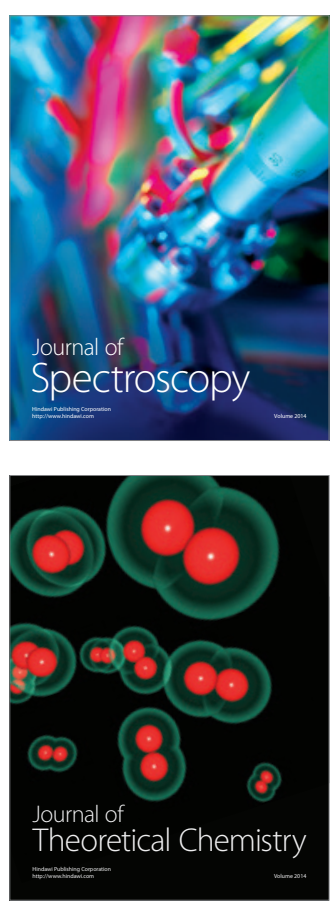
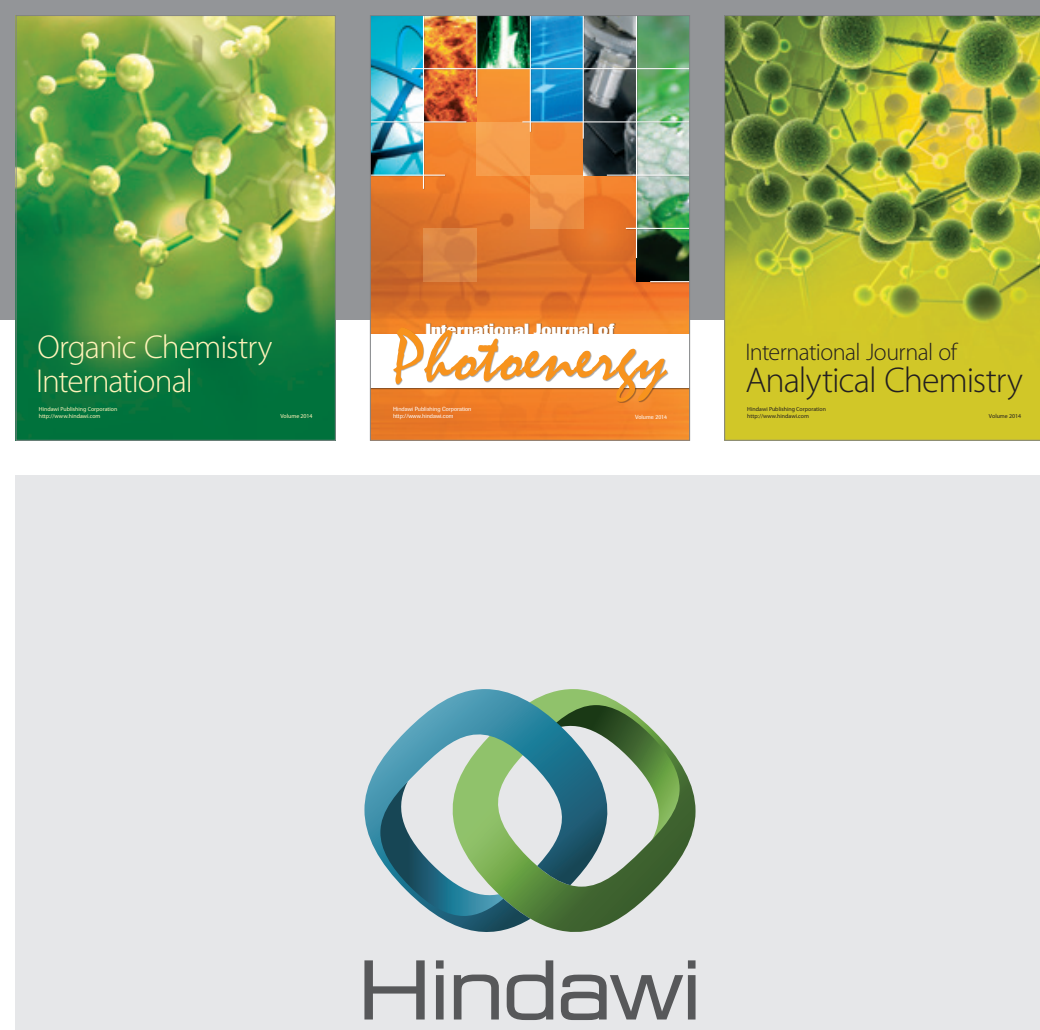

Submit your manuscripts at

http://www.hindawi.com
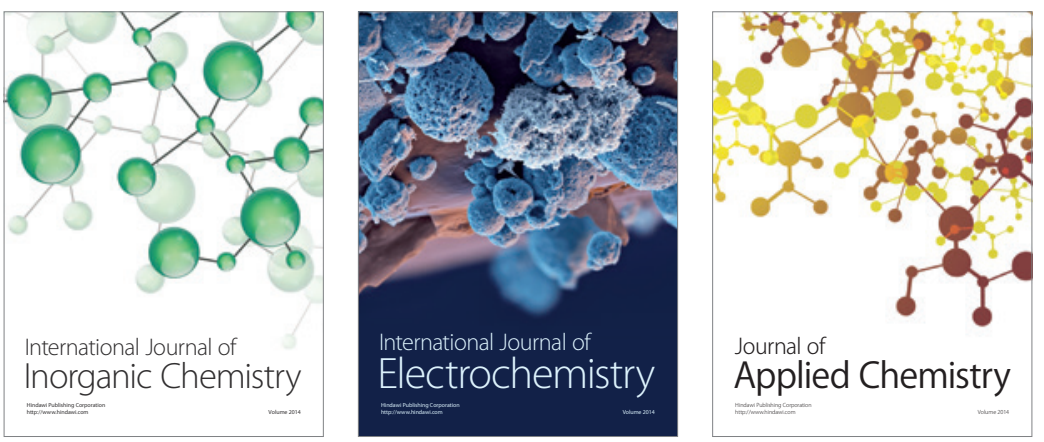

Journal of

Applied Chemistry
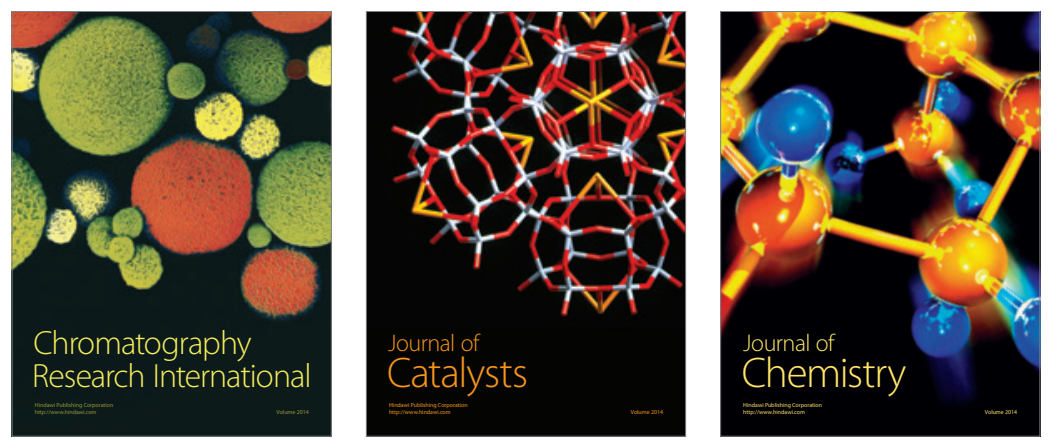
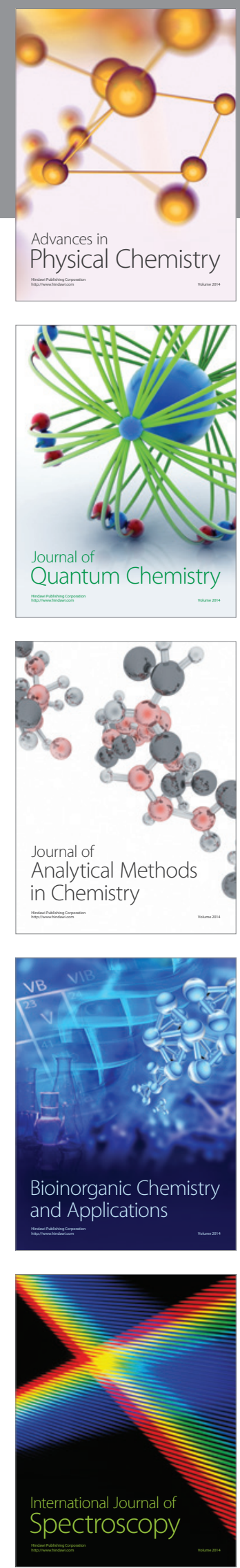